\title{
Biofabrication and Bone Tissue Regeneration: Cell Source, Approaches, and Challenges
}

\author{
Monia Orciani', Milena Fini ${ }^{2}$, Roberto Di Primio ${ }^{1}$ and Monica Mattioli-Belmonte ${ }^{1 *}$ \\ ${ }^{1}$ Department of Molecular and Clinical Sciences, Università Politenica delle Marche, Ancona, Italy, ${ }^{2}$ Laboratory of Preclinical \\ and Surgical Studies, Rizzoli Orthopedic Institute, Bologna, Italy
}

OPEN ACCESS

Edited by:

Giovann Vozzi,

University of Pisa, Italy

Reviewed by:

Senentxu Lanceros-Mendez,

University of Minho, Portugal

Krishna Chandra Persaud,

University of Manchester, UK

${ }^{*}$ Correspondence:

Monica Mattioli-Belmonte

m.mattioli@univpm.it

Specialty section:

This article was submitted to

Bionics and Biomimetics,

a section of the journal

Frontiers in Bioengineering and

Biotechnology

Received: 28 October 2016

Accepted: 22 February 2017

Published: 23 March 2017

Citation:

Orciani M, Fini M, Di Primio $R$ and Mattioli-Belmonte M (2017)

Biofabrication and Bone Tissue Regeneration: Cell Source, Approaches, and Challenges. Front. Bioeng. Biotechnol. 5:17. doi: 10.3389/fbioe.2017.00017
The growing occurrence of bone disorders and the increase in aging population have resulted in the need for more effective therapies to meet this request. Bone tissue engineering strategies, by combining biomaterials, cells, and signaling factors, are seen as alternatives to conventional bone grafts for repairing or rebuilding bone defects. Indeed, skeletal tissue engineering has not yet achieved full translation into clinical practice because of several challenges. Bone biofabrication by additive manufacturing techniques may represent a possible solution, with its intrinsic capability for accuracy, reproducibility, and customization of scaffolds as well as cell and signaling molecule delivery. This review examines the existing research in bone biofabrication and the appropriate cells and factors selection for successful bone regeneration as well as limitations affecting these approaches. Challenges that need to be tackled with the highest priority are the obtainment of appropriate vascularized scaffolds with an accurate spatiotemporal biochemical and mechanical stimuli release, in order to improve osseointegration as well as osteogenesis.

Keywords: bone regeneration, cell source, biofabrication, biocompatibility, stem cells and regenerative medicine

\section{INTRODUCTION}

Bone is composed of bone tissue and bone marrow encased within the periosteum, a thin strip of soft tissue that envelops the midshafts of long bones, extending to their proximal and distal metaphyses and adjacent epiphyses (Malizos and Papatheodorou, 2005). Bone has the ability to self-repair and regrowth: postnatal bone maintains an intrinsic ability for well-ordered growth, remodeling to satisfy mechanical needs, and renewal after damages.

Abbreviations: ALP, alkaline phosphatase; AMTs, additive manufacturing technologies; ASCs, adipose tissue-derived stem cells; BM-MSCs, bone marrow stromal cells; BMP, bone morphogenetic protein; CAD, computer-assisted design; CNTs, carbon nanotubes; CT, X-ray computed tomography; ECM, extracellular matrix; EPC, endothelial progenitor cells; FGF, fibroblast growth factor; HUVEC, human umbilical vein cells; IGF, insulin-like growth factor; MAPK, mitogen-activated protein kinase; MRI, magnetic resonance imaging; MSCs, mesenchymal stromal cells; PAM, pressure-activated microsyringe; PCL, polycaprolactone; PDGF, platelet-derived growth factor; PANI, polyaniline; PEGDMA, poly(ethylene glycol) dimethylacrylate; PEG-PLGA, poly (ethylglycol)-poly (lactic-co-glycolic acid); PHAs, polyhydroxyalkanoates; PLGA, poly (lactic-co-glycolic acid); $\mu \mathrm{CT}$, microcomputed tomography; PPy, polypyrrole; PTH, parathyroid hormone; PTHrH, parathyroid hormone-related protein; SEM, scanning electron microscopy; S-MSCs, skin-derived multipotent stromal cells; SPECT, single-photon gamma rays; STL, Standard Tessellation Language; 3D, three dimensional; TEM, transmission electron microscopy; TGF, transforming growth factor; VEGF, vascular endothelial growth factor. 
In large bone defects (caused by significant trauma or systemic disease, pathological fractures, non-union, infections or compromised blood supply) this capability can however fail, resulting in permanent defects that can lead to a loss of function. Bone regenerative ability declines with age; therefore, there is a need for ad hoc treatments in patients with skeletal diseases determined by the rise in population aging. It must be also stressed that the next most transplanted tissue after blood is bone (Leach and Mooney, 2004; Oryan et al., 2014).

In bone defect treatments, the "gold standard" remains bone grafting (Brydone et al., 2010): bone graft could be used alone or in combination with other materials in order to promote bone healing through osteoinduction, osteoconduction, and osteogenesis. An ideal bone graft can be in the form of autograft (harvested from the patient), allograft, or xenograft (obtained from a donor or animal), or represented by the use of an engineered synthetic biomaterial (Gibbs et al., 2014). Table 1 summarized the advantages and disadvantages of possible different bone grafts (Tang et al., 2016).

The intrinsic reparative capacity of bone grafts represent the natural model to reproduce when using new therapeutic options in tissue engineering strategies: appropriate scaffolds, growth factors, and/or cells, has, in some cases, improved grafts incorporation, osteoconductivity, osteoinductivity, and osseointegration (Kundu et al., 2014). Scaffolds must support cell colonization, proliferation, differentiation, and migration. They usually entail a solid load carrying structure with an intersected pore network, whereas hydrogels containing encapsulated cells often form the "matrix" (Bose et al., 2012). Scaffolds should possess appropriate physicochemical properties (i.e., stiffness, biodegradability, surface chemistry, etc.) that are essential for tissue formation and be capable to face mechanical stresses (Table 2).

\section{CELL SOURCE}

Cells are commonly used to repair injured tissue, as they are physiologically involved in tissue development and homeostasis. Osteoblast and osteocyte are the key regulators of bone deposition, modeling, and remodeling. Therefore, osteoblasts and/or their precursors represent an excellent cell source for a successful cell-based skeletal treatment.

The incorporation of mesenchymal stromal cells (MSCs) into bone tissue engineering strategies has been a crucial progress. The most frequently used are bone marrow stromal cells (BM-MSCs) (Oreffo et al., 2005; Robey, 2011; Dawson et al., 2014), given to the fact that they have been broadly studied, but several different sources have also been exploited (Table 3).

Viable alternatives to BM-MSCs are represented by adipose tissue-derived stem cells (ASCs) and oral cavity MSCs. ASCs have a documented in vitro osteogenic aptitude (El Tamer and Reis, 2009), ease of access, and abundance (Szpalski et al., 2012) and, moreover, survive in low oxygen and/or glucose environments. The latter aspects are an intriguing advantage when the blood and nutrient supply are limited, like with biofabricated bone constructs. Oral cavity MSCs have been exploited for bone tissue engineering strategies (Orciani et al., 2012; Liu et al., 2015a,b) and also proposed for biofabrication of bone (El Tamer and Reis, 2009; Wang et al., 2011; Zhu and Liang, 2015).

Another attractive stem cell reservoir that could meet bone tissue engineering criteria is the skin basal layer (Takeda et al., 1992; Orciani and Di Primio, 2013). The so-called skin-derived multipotent stromal cells, isolated from this site, show multipotent differentiation ability, and are capable to become adipocytes, osteoblasts, chondrocytes, neurons, and pancreatic cells (Orciani et al., 2010). These features in combination with their immunosuppressive effect make them an ideal challenger for various cell transplantation therapies (Vishnubalaji et al., 2012).

The growth, development, and regeneration of bone as well as cartilage rest on periosteum presence. This tissue is pluripotent (Arnsdorf et al., 2009) and may be used for engineering in vivo new bone formation (Castro-Silva et al., 2012; Ferretti and Mattioli-Belmonte, 2014). Osteoblasts and chondroblasts of periosteum are well characterized in terms of function, gene expression, cell and extracellular protein synthesis, and secretion as well as structural organization for the elaboration of bone and cartilage, respectively (Colnot, 2011; Mafi et al., 2011). Fewer investigations are relative to the nature and role of periosteum in the bone and cartilage formative and repair processes, or to possible differences and effects of various periosteum sources on

TABLE 1 | Advantages and disadvantages of different bone grafts. ${ }^{a}$

\begin{tabular}{|c|c|c|}
\hline & Advantages & Disadvantages \\
\hline Allograft or xenograft & $\begin{array}{l}\text { Osteoconductive } \\
\text { Osteoinductive } \\
\text { High availability } \\
\text { No donor site morbidity }\end{array}$ & $\begin{array}{l}\text { Lack of osteogenicity and vascularization } \\
\text { Relatively higher rejection risk } \\
\text { Risk of disease transmission } \\
\text { High cost }\end{array}$ \\
\hline Engineered grafts & $\begin{array}{l}\text { Capability to integrate growth factors and } \\
\quad \text { stem cells for osteogenicity and graft } \\
\text { incorporation improvement } \\
\text { Shaped to fit site defects } \\
\text { No donor site morbidity }\end{array}$ & $\begin{array}{l}\text { Osteogenicity limited by material porosity (due to manufacturing process) } \\
\text { Variable biodegradability of different materials } \\
\text { Poor neovascularization } \\
\text { Unknown immune response } \\
\text { Limited mechanical properties }\end{array}$ \\
\hline
\end{tabular}

a Modified from Gibbs et al. (2014) and Tang et al. (2016). 
TABLE 2 | Scaffold features for bone tissue engineering strategies. ${ }^{\text {a }}$

Biocompatibility

Biodegradability (bioresorbability)

Pore size and porosity

Mechanical properties
Capability to support normal cell activity with no toxic effect in host tissues particularly during degradation

Osteoconductive, osteoinductive, and osteogenic properties

Ability to promote angiogenesis for new blood vessels formation around the implant are advisable

Controlled degradation of a scaffold with time is mandatory to generate space for the growth of new bone tissue and, eventually, the replacement of the synthetic scaffold

Degradation rate of can be tailored to the application required (e.g., controlled release of biomolecules)

Critical feature for the diffusion of oxygen and nutrients for cell survival and proliferation

Minimum pore size of $100 \mu \mathrm{m}$

Pore sizes of 200-350 $\mu \mathrm{m}$ are optimal for bone tissue ingrowth

Meso-porous structures (micro- and macro-porosities mixture) are better than macro-porous ones in supporting cell adhesion

Porosity influences scaffold's mechanical strength

Should be in line with host bone properties in facing mechanical stress and reacting to load transfers Differences in the topography and mechanical characteristics between cortical and trabecular bone affect scaffold design

aModified from Tang et al. (2016) and Bose et al. (2012).

TABLE 3 | Mesenchymal stromal cells (MSCs) in bone tissue engineering. ${ }^{a}$

\begin{tabular}{|c|c|c|c|}
\hline & $\begin{array}{l}\text { Potential for bone tissue } \\
\text { engineering }\end{array}$ & Advantages & Disadvantages \\
\hline Bone marrow & $\begin{array}{l}\text { Osteogenic } \\
\text { Potential for neovascularization }\end{array}$ & $\begin{array}{l}\text { Relatively easy acquisition } \\
\text { In situ recruitment } \\
\text { Well-characterized }\end{array}$ & $\begin{array}{l}\text { Donor morbidity } \\
\text { Limited proliferative potential } \\
\text { Fewer cells compared to other sources } \\
\text { Cell number } \\
\text { Related to age and health of donor }\end{array}$ \\
\hline Adipose tissue & $\begin{array}{l}\text { Osteogenic } \\
\text { Potential for neovascularization }\end{array}$ & $\begin{array}{l}\text { Easy acquisition } \\
\text { Well-characterized }\end{array}$ & Donor morbidity (due to anesthesia) \\
\hline $\begin{array}{l}\text { Oral cavity MSCs (dental pulp, } \\
\text { periodontal ligament) }\end{array}$ & Osteogenic & $\begin{array}{l}\text { Abundant } \\
\text { Easy acquisition }\end{array}$ & Not well-characterized \\
\hline Skin & $\begin{array}{l}\text { Potential for neovascularization } \\
\text { Support to osteogenic differentiation }\end{array}$ & $\begin{array}{l}\text { Abundant } \\
\text { Minimal donor morbidity }\end{array}$ & Not well-characterized \\
\hline Periosteum & Osteogenic & $\begin{array}{l}\text { Well-characterized } \\
\text { In situ recruitment } \\
\text { Can be co-seeded with bone marrow- } \\
\text { derived stem cells }\end{array}$ & Cell number and activity related to donor age \\
\hline
\end{tabular}

aModified from Tang et al. (2016).

osteogenesis and chondrogenesis. As far as animal is concerned, periosteum from only certain bones and at different ages was examined (O'Driscoll and Fitzsimmons, 2001; O'Driscoll et al., 2001; Fan et al., 2008), and results of these and related studies (Kwon et al., 2002; Szulc et al., 2006) could not be easily correlated. Moreover, the analysis of tissues from different anatomical regions of single calves showed that each periosteum retained its own gene expression, protein and proteoglycan secretion, growth, and development (Kusuhara et al., 2009). In 2011, Matsushima and co-workers compared the osteogenic and chondrogenic potential of periosteal tissue harvested from individual young calve sites undergoing intramembranous (cranium and mandible) or endochondral ossification (radius and ilium) by implantation as tissue-engineered constructs in nude mice. They demonstrated that the osteogenic and chondrogenic ability of the different constructs depended on the periosteal source, regardless of intramembranous or endochondral ossification, as cranial and mandibular periosteal tissues were able to enhance bone formation most and least conspicuously, respectively (Matsushima et al., 2011).
In humans, recent researches have been devoted to the evaluation of periosteal cells differentiation ability in response to mechanical, chemical (e.g., growth factors) stimuli as well as in cocultures (Ferretti et al., 2014; Mattei et al., 2015; Dicarlo et al., 2016). Moreover, researches related to possible changes associated with donor age showed that this parameter affects periostealderived stem cell behavior mainly in term of bone remodeling (Ferretti et al., 2014).

The influence of stem cells has been tested in animal models; however, it is still unclear whether these cells do retain the in vivo capacity to form bone (Marolt et al., 2010). At last, in order to meet the good manufacturing practice standards, a well-defined, standardized protocol for the isolation and in vitro manipulation of these cells is still necessary (Seong et al., 2010; Tare et al., 2012).

Angiogenesis is critical in creating a viable biofabricated bone construct, for this reason, the use of two, rather than one, cell types has gathered much interest in bone tissue engineering strategies (Kyriakidou et al., 2008) (Figure 1). For instance, BM-MSCs were used to generate blood vessels also seeded onto a scaffold with endothelial cells (Fedorovich et al., 2010; Gao et al., 2014). 
Indeed, the inefficient stimulus for a rapid development of new blood vessels that invade the coculture grafts may explain the fail in proving bone formation using this method (Liu et al., 2015a,b; Unger et al., 2015), making this approach still limited.

\section{BIOCHEMICAL SIGNALING FOR BONE BIOFABRICATION}

Bone tissue engineering has tried to exploit the regenerative properties of bone physiological processes (Table 4). In vivo, biochemical signals (i.e., growth factors, hormones, and cytokines), secreted locally in the areas undergoing bone remodeling or at the injury sites, cause the migration of inflammatory and precursor cells and/or the activation of osteoblasts and osteoclasts (Kanczler and Oreffo, 2008). Activation of bone-forming and resorbing cells determine to new bone generation during the healing or the remodeling process, respectively. Clinical studies usually utilize growth factors at the range of milligrams per milliliter instead of nanograms per milliliter: this results in adverse effects such as ectopic bone formation, antibody development, and, as latter event, carcinogenesis. Indeed, conflicting data on the appropriate doses of growth factors for bone tissue engineering strategies are available, with a broad range of concentrations in use (Gothard et al., 2014). Moreover, it is still unclear (i) which dose of growth factors is actually delivered in vivo by the constructs within a bone defect (Santo et al., 2013) and (ii) the effects of the co-use of multiple growth factors (Young et al., 2009; Kuhn et al., 2013).

Delivery of biochemical cues can be obtained in different ways: unbound, bound within the implant for a controlled delivery, coated on the implant surface, or coded within the cells via gene delivery mechanisms (Zhang et al., 2010; Catros et al., 2012). In the first case, we observe a burst release of growth factors, resulting in a rapid clearance from the microenvironment: this technique may be appropriate for an immediate stimulus and it is strictly dependent on the biomaterial degradation rate. Physical entrapment or covalent binding is a more appropriate approach when a prolonged, more controlled, or on-demand release of the growth factor or drug is required (Zhang et al., 2010; Mourino et al., 2013). With these techniques, a sustained release over a 15-day period was demonstrated for active lysozyme enclosed within thermoresponsive PLGA microspheres incorporated into extrusion printed PEG-PLGA constructs (Sawkins et al., 2015).

Three-dimensional (3D) printing methods can create bioactive or bioinstructive scaffolds, incorporating growth factors or drugs with a spatiotemporal distribution. For instance, the spatial patterns of bone morphogenetic protein (BMP)-2, generated on a fibrin surface using an inkjet bioprinter, was able to differently affect murine muscle-derived stem cells: cells seeded onto the BMP-2 pattern undergo osteogenic differentiation as evidenced by alkaline phosphatase activity, while those seeded outside the BMP-2 pattern remain undifferentiated (Phillippi et al., 2008). A reduction in biological activity of bioprinted recombinant human BMP-2 was also observed (Vorndran et al., 2010). Since the majority of growth factors have an in vivo short half-life, it is important to take into consideration both the biochemical molecule properties and scaffold features.

Currently, in tissue engineering, hydrogels are the most investigated polymers for cell encapsulation and biochemical cues in situ delivery. Molecules such as BMP-2 and transforming growth factor- $\beta 3$ were incorporated into alginate hydrogels designed to degrade at different rates by gamma-irradiation, and the effect of single and dual growth factors delivery on encapsulated rat BM-MSCs was investigated. The appropriate controls of scaffold degradation rate made possible the modulation of osteogenesis (Simmons et al., 2004). In order to mimic the function performed by the extracellular matrix (ECM), bioactive hydrogels containing protease sensitive sites, cell adhesion molecules such as
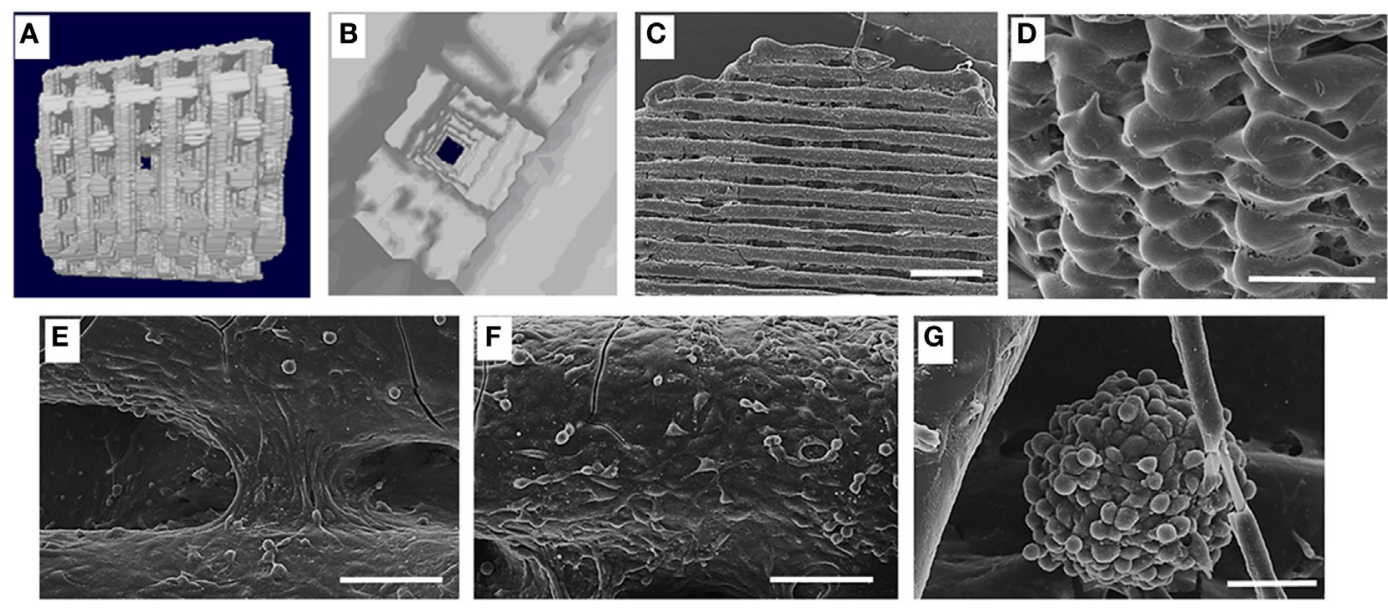

FIGURE 1 | (A) Lateral view of three-dimensional (3D) fiber deposited polycaprolactone (PCL) scaffold reconstruction; (B) inners structure of the same scaffold; (C) colonization of the 3D PCL scaffold in dynamic condition; scale bar $1 \mathrm{~mm}$; (D) high magnification showing the external cell monolayer, scale bar $1 \mathrm{~mm}$; (E) cells bridging the grooves, scale bar $100 \mu \mathrm{m}$; (F) cell arrangement suggestive of a new vascular structure, scale bar $100 \mu \mathrm{m}$; (G) spheroid of MC63 and human umbilical vein cells generated in dynamic condition scale bar $50 \mu \mathrm{m}$ [from Kyriakidou et al. (2008)]. 
TABLE 4 | Growth factors and bone tissue engineering. ${ }^{a}$

\begin{tabular}{|c|c|c|}
\hline Growth factor & Tissues & Effects \\
\hline $\begin{array}{l}\text { Bone morphogenetic } \\
\text { protein (BMP) } 2 \text { and } 7\end{array}$ & $\begin{array}{l}\text { Bone, } \\
\text { cartilage }\end{array}$ & $\begin{array}{l}\text { Osteoblast differentiation and migration } \\
\text { Accelerated bone healing }\end{array}$ \\
\hline $\begin{array}{l}\text { Fibroblast growth } \\
\text { factors } 1,2 \text {, and } 18\end{array}$ & $\begin{array}{l}\text { Bone, } \\
\text { muscle, } \\
\text { blood vessel }\end{array}$ & $\begin{array}{l}\text { Endothelial cell migration, proliferation, } \\
\text { and survival } \\
\text { Increased osteogenic differentiation of } \\
\text { mesenchymal stromal cells }\end{array}$ \\
\hline $\begin{array}{l}\text { Insulin-like growth } \\
\text { factor-1 }\end{array}$ & $\begin{array}{l}\text { Bone, } \\
\text { cartilage, } \\
\text { muscle }\end{array}$ & $\begin{array}{l}\text { Osteoprogenitor cell proliferation and } \\
\text { differentiation }\end{array}$ \\
\hline $\begin{array}{l}\text { Platelet-derived } \\
\text { growth factor (PDGF)- } \\
\text { AA and PDGF-BB }\end{array}$ & $\begin{array}{l}\text { Bone, } \\
\text { cartilage, } \\
\text { blood vessel, } \\
\text { muscle }\end{array}$ & $\begin{array}{l}\text { Endothelial cell proliferation, migration, } \\
\text { and growth } \\
\text { Osteoblast replication in vitro } \\
\text { Type } 1 \text { collagen synthesis }\end{array}$ \\
\hline $\begin{array}{l}\text { Parathyroid hormone } \\
\text { and parathyroid } \\
\text { hormone-related } \\
\text { protein }\end{array}$ & Bone & $\begin{array}{l}\text { Intermittent dosage } \rightarrow \text { stimulation of } \\
\text { osteoblasts } \rightarrow \text { increased bone formation } \\
\text { Continuous administration } \rightarrow \text { bone } \\
\text { resorption }\end{array}$ \\
\hline $\begin{array}{l}\text { Transforming growth } \\
\text { factor- } \beta 3\end{array}$ & $\begin{array}{l}\text { Bone, } \\
\text { cartilage }\end{array}$ & $\begin{array}{l}\text { Bone-forming cell proliferation and } \\
\text { differentiation } \\
\text { Enhancement of in vivo hyaline cartilage } \\
\text { formation } \\
\text { Antiproliferative effect on epithelial cells }\end{array}$ \\
\hline $\begin{array}{l}\text { Vascular endothelial } \\
\text { growth factor }\end{array}$ & $\begin{array}{l}\text { Bone, blood } \\
\text { vessel }\end{array}$ & $\begin{array}{l}\text { Enhancement of vasculogenesis and } \\
\text { angiogenesis (functionality of vasculature } \\
\text { is concentration dependent) } \\
\text { Reduction or increase in bone formation } \\
\text { dependent on concentration when used } \\
\text { in combinational with BMP-2 delivery }\end{array}$ \\
\hline
\end{tabular}

${ }^{a}$ Adapted from Tang et al. (2016) and Gothard et al. (2014).

RGD-containing peptides, and/or biological cues in the form of growth factors, inorganic minerals, or drugs, were also developed (He et al., 2008; Fedorovich et al., 2011).

Vascular endothelial growth factor (VEGF) plays a key role in angiogenesis during bone development. Several studies investigated the consequence of VEGF, or of a combination of growth factors, on angiogenesis in engineered bone constructs. The co-immobilization of VEGF and angiopoietin-1 on 3D porous collagen scaffolds increased endothelial cell proliferation in vitro and in organotypic cultures (Chiu and Radisic, 2010). Studies on synergistic or cumulative effect of VEGF and of insulin-like growth factor underlined as these molecules elicit different cell response in term of bone formation and angiogenesis in relation to the stem cell origin (Ferretti et al., 2014; Dicarlo et al., 2016). Moreover, this different commitment is linked to a diverse mitogen-activated protein kinase or PI3K/AKT signaling pathway activation (Figure 2) [see Ferretti et al. (2014) and Dicarlo et al. (2016) for details].

\section{ADDITIVE MANUFACTURING TECHNOLOGIES (AMTS), BIOFABRICATION, AND BONE TISSUE ENGINEERING STRATEGIES}

Rapid prototyping or solid freeform fabrication (i.e., AMT) was developed in the mid-1980s, providing a high level of control of the construct architecture, flexibility to scale-up fabrication, and assuring reproducibility and standardization of the manufacturing process. Scaffolds developed using conventional fabrication techniques lacks in precision and reproducibility; on the contrary, AMT provides customized scaffolds with precise geometries for replacing damaged or diseased tissues and organs. AMT enables the production of $3 \mathrm{D}$ artificial implants using many biomaterials able to meet rigorous performance criteria for clinical use (Hutmacher and Cool, 2007) as indicated in the growing use of 3D printed artificial implants instead of traditional metallic ones in hip replacement surgery. In recent years, the increasing attention in generating a high personalized and cost-effective medical therapy not only resulted in the growing use of AMT in the manufacture of 3D tissue-engineered structures (Melchels et al., 2012) but has also determined improvement within AMT techniques.

Usually, AMT allows the setup of 3D objects by means of data generated by computer-assisted design (CAD) software or imported from clinical 3D scanners such as X-ray computed tomography, magnetic resonance imaging, and single-photon gamma rays (SPECT). The CAD model is then transformed to a Standard Tessellation Language (STL) file that guides the 3D printer computer system to generate layer-by-layer the object. The manufacturing of a variety of biomaterials fitting the different AMTs allowed the development of scaffolds with tunable properties (Melchels et al., 2012). The American Society for Testing and Materials International Committee F42 on AMT has divided these technologies into seven different processes, which are in line with the layer deposition and bonding techniques [see Gibbs et al. (2014) and Tang et al. (2016) for details].

At present, cell-based treatments are not yet available for clinical use despite the advances in biofabrication and they rely on manual cell seeding and culturing of pre-fabricated scaffolds (Ferris et al., 2013). The current cell-based therapies are only applicable on a limited scale, since they are operator dependent, time consuming, and often inefficient. Moreover, cell seeding on pre-fabricated scaffolds does not recreate the cell organization of native tissues also in term of vascularization. To address these issues and improve cell spatial distribution within the scaffold, cells could be incorporated by an AMT termed as biofabrication, in order to create living cell/biomaterial/biomolecule constructs.

In bone tissue engineering, biofabrication techniques could provide a means to control uniformity of cell distribution or localization on the scaffold surface (Guillotin et al., 2010; Fedorovich et al., 2012). Moreover, the integration of growth factors within the cellular matrix and/or their incorporation inside the scaffold itself during the printing process provides a method for a controlled drug delivery and release (Khatiwala et al., 2012; O’Brien et al., 2014; Tang et al., 2016).

In bone, cells are at different stages of proliferation, differentiation, and maturation inside multi-layered organized ECM. By biofabrication, it is possible to bioprint cells onto a suitable scaffold to create bone with the ability to maintain cell functional capability as well as allowing bone remodeling (Fedorovich et al., 2011).

Biofabrication could provide a more cost-effective manner for the treatment of patients with musculoskeletal defects or 


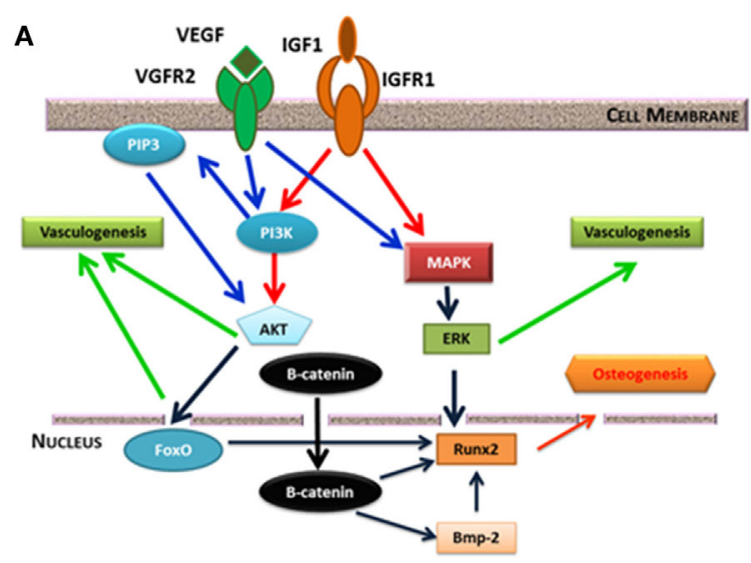

B

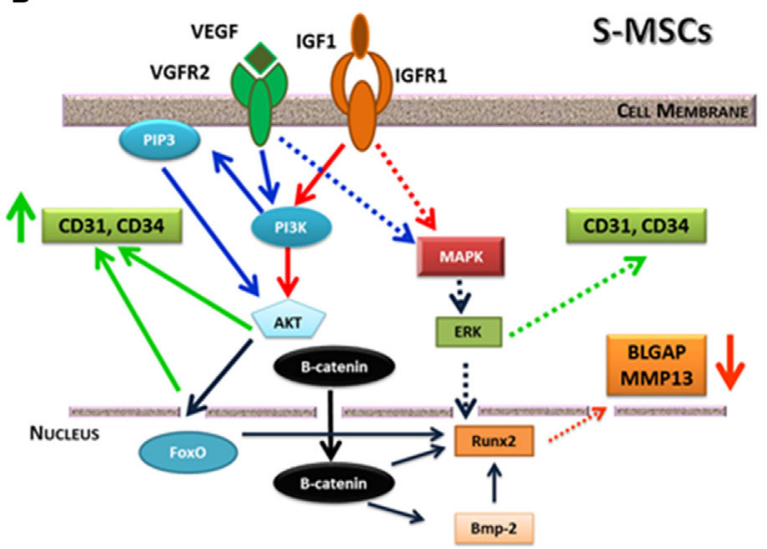

C

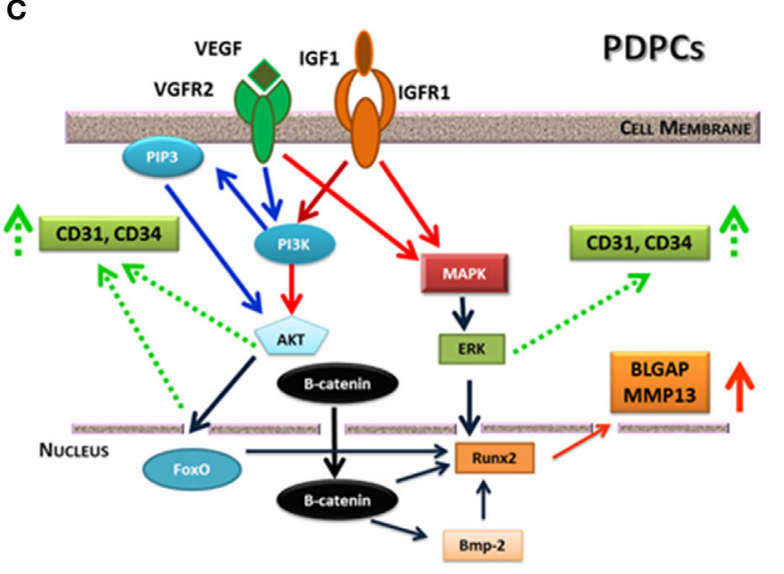

FIGURE 2 | (A) Possible interplay between insulin-like growth factor (IGF)-1 and vascular endothelial growth factor (VEGF) receptor signaling pathways. They equally converge on ERK kinase, which fine-tune the activity of the main osteogenic transcription factor Runx2. IGF1 and VEGF also trigger PI3/AKT signaling pathway that can induce vasculogenesis or beta-catenin phosphorylation. On the contrary, non-phosphorylated beta-catenin acts as a pro-osteogenic factor regulating Runx2 and other genes. (B) consequences of IGF1 or IGF1/NEGF treatment on skin-derived multipotent stromal cells (S-MSCs) gene expression suggesting their commitment toward the endothelial phenotype. (C) Consequences of IGF1 or IGF1/NEGF treatment on PDPCs showing their main commitment toward the osteoblastic phenotype. Continuous lines indicate a marked effect, while dotted lines suggest a weaker regulation. Modified from Ferretti et al. (2014).

disease in addition to offer a new therapeutic option for patients who cannot be cured with traditional therapy. The possibility to seed cells and biomolecules in a 3D space, with an improving better degree of detail and in a user-controlled, predefined way is a key biofabrication breakthrough over traditional approaches (Table 5). Indeed, accurate printing supports the manufacturing of a customized 3D structure that closely fit the defect, thereby decreasing engraftment chances or injury misrepair. Finally, biofabricated bone will remove the donor bone graft requirement, thereby permitting to the patients to undergo surgery earlier (thus reducing waiting list times while recovering mobility earlier), and with a reduced risk of physical and psychological morbidity. The chance of rejection of a biofabricated bone tissue is further reduced by the use of autologous cells.

Several AMTs have been experienced to manufacture 3D scaffolds, and more recently, in the printing of tunable hydrogels for bone tissue engineering. Table $\mathbf{6}$ summarized some of the AMTs used in bone tissue engineering.
In microextrusion deposition method, thin thermoplastic grains or filaments are wormed up until melting and then piloted by a controlled robotic device, to generate the $3 \mathrm{D}$ construct. The fused material is extruded and then it hardens immediately. A temperature just below the solidification point of the material must be maintained in order to guarantee the good interlayer adhesion (Melchels et al., 2012). Fedorovich et al. (2008) demonstrated the possibility to generate with this procedure bone grafts by depositing 3D fibers composed of various hydrogels and goat BM-MSCs with no damage to cells in term of osteogenic differentiation during the printing process. In another study, they developed heterogeneous hydrogel constructs with endothelial progenitor cells and goat multipotent stromal cells to promote neovascularization during bone regeneration (Fedorovich et al., 2010).

Pressure-activated microsyringe (PAM) fabrication is a peculiar microextrusion technique in which the polymer is distributed through a tool-head installed on an arm or on the $z$-axis of a 
TABLE 5 | Applications, advantages, and limitations of printing stem cells and biomolecules. ${ }^{a}$

\begin{tabular}{|c|c|c|}
\hline & Cells & Biomolecules \\
\hline Applications & $\begin{array}{l}\text { Stem cell genomics } \\
\text { Patches for wound healing } \\
\text { Ex vivo generation of tissue replacement }\end{array}$ & $\begin{array}{l}\text { Protein and DNA arrays } \\
\text { Tissue engineering uses }\end{array}$ \\
\hline Advantages $^{b}$ & $\begin{array}{l}\text { Programmable } \\
\text { Low cost } \\
\text { Three-dimensional complexity } \\
\text { High throughput }\end{array}$ & $\begin{array}{l}\text { Programmable } \\
\text { Low cost } \\
\text { Non-contact, reducing risk of cross-contamination from surface } \\
\text { No modification required for proteins or substrates }\end{array}$ \\
\hline Disadvantages & $\begin{array}{l}\text { Cytocompatibility in both solid and liquid forms } \\
\text { Viscosity has to be lower than a threshold as defined by } \\
\text { the printing method }\end{array}$ & $\begin{array}{l}\text { Lower resolution compared to state-of-the-art protein array } \\
\text { Number of available binding sites on the receiving substrate } \\
\text { Cytocompatibility } \\
\text { Viscosity }\end{array}$ \\
\hline
\end{tabular}

aModified from Tang et al. (2016).

${ }^{b}$ Compared to conventional methods.

TABLE 6 | Classification and applications of additive manufacturing technology (AMT). ${ }^{a}$

Stereolithography

Two-photon polymerization

Drop on-demand inkjet printing

Poly-jet technology

Non-melting extrusion

3D bio plotting

Solvent-based extrusion free-forming

Robocasting

Direct-write assembly

Electrospinning

Pressure-activated microsyringe

Melting extrusion

Fused deposition modeling

3D fiber deposition

Multiphase jet solidification

Selective laser sintering

Selective laser melting

Electron beam melting

Selective mask sintering

Laser engineering net shape

Laser cladding

Directed metal deposition

Laminated object manufacturing

Ultrasonic consolidation

3D printing
Fast

Wide range of biomaterials Inexpensive existing technology Fabrication of composite structures Multi-cell printing

Cheap mechanism with relatively good throughput

No post-processing needed

Low material waste

Cytocompatible

Rapid

Non-toxic materials with good properties

\section{Disadvantages}

Single composition

Cytotoxic photo-initiator

Photopolymer materials only

Post-processing mandatory

Limited cell printing ability

Heterogeneous cell distribution

Nozzle blockage common

Low bioink viscosity limits improvement of $3 \mathrm{D}$ constructs

Poor mechanical strength of $3 D$ constructs

Low accuracy

Poor mechanical strength

Precise control of ink rheology necessar

Use of solvents

Low accuracy

Weak bonding between dissimilar polymer layers

\section{Applications}

Clinical implants

Surgical guides

Tissue engineering scaffolds

Cell-incorporated three-dimensional (3D) constructs

3D microvasculature networks

Clinical implants

Surgical guides

Tissue engineering scaffolds

Cell-incorporated 3D constructs

Biofabrication

Tissue engineering scaffolds

Cell-incorporated 3D constructs

Biofabrication

Clinical implants

Tissue engineering scaffolds
Wide range of biomaterials High material strength Good material properties

Wide range of biomaterials Good material properties

Low temperature process

Low temperature process

Fast

Fabrication of composite structures
Thermal stress and degradation Accuracy limited by particle size Atmosphere control needed for metal printing

Low accuracy

Thermal stress

Atmosphere control needed for machining process

Shrinkage

Significant waste

Delamination

Powders are necessary

Powder entrapment

High porosity

Low surface quality

Accuracy restricted by particle size

Cell-changing environment
Surgical implants with complex structure Tissue-engineered scaffold

Medical devices

Orthopedic implants

Orthopedic implants

Clinical implants

Tissue engineering scaffolds

aModified from Tang et al. (2016). 
computer-controlled 3D micropositioner. The achieved scaffold resolution is normally a function of the polymeric system viscosity, the motor speed, the physical principle that permits polymer distribution, and the nozzle geometry (Vozzi et al., 2002; Tirella et al., 2012). This technique has been used to modulate different cell cytotype behavior in response of topological features (Mattioli-Belmonte et al., 2008) and, more recently, to generate bioactive glass-poly(lactic-co-glycolic acid) (PLGA) scaffolds mirroring the topological characteristics of cancellous bone (Mattioli-Belmonte et al., 2015).

Laser-assisted bioprinting involve a pulsed laser source, a receiver substrate for patterning and collecting cells and biomaterials, and a target. An essential element is a laser-absorbing interlayer with a high heat transfer coefficient. Individual cells in suspension are "driven" by directed laser beams and deposited onto a solid surface. This cell-by-cell deposition enables a precise cell micropatterning and improves cell interactions (Melchels et al., 2012; Guillotin et al., 2014). This technique was used to bioprint human osteosarcoma cells (MG63) onto a bio-polymeric matrix (Barron et al., 2005) and to create an on-demand pattern of nano-hydroxyapatite and human osteoprogenitor cells (Catros et al., 2011). The majority of cells survived throughout the printing process (Catros et al., 2012) and the layer-by-layer assembly method exceeded the seeding a single locus of the scaffold during the creation of a 3D construct (Tang et al., 2016).

At last, the inkjet-based cell printing is a useful, simple, and low-cost method providing microenvironmental cues to cells in order to increase cell survival or manipulate their morphofunctional behavior. This technique is able to generate microscale organization of deposited cells (Cui and Boland, 2009) without compromising their viability or inducing damage to cell phenotype or genotype (Gao et al., 2014). Inkjet-based cell printing could be used to fabricate complex multicellular constructs, since it allows the simultaneous printing of multiple cell types together with biomolecules alongside biomaterials. Inkjet-based printing is one of the methods used to make cell-laden hydrogels (Ferris et al., 2013). With this technology, Gao et al. (2014) demonstrated that encasing human MSCs in poly(ethylene glycol) dimethylacrylate (PEGDMA), containing either bioactive glass or hydroxyapatite nanoparticles, cells were viable post-printing and a greater osteogenesis was present in the construct containing hydroxyapatite.

\section{SELECTING A BIOMATERIAL}

Scaffolds generated with AMT are generally made of ceramic, metal, self-assembly peptides, and synthetic or natural polymers (Stevens et al., 2008; Leijten et al., 2015). Due to the specific advantages and disadvantages of each type of biomaterial, the use of composite scaffolds is becoming more common. Several reviews have comprehensively addressed the most common combinations biomaterials as well as their in vitro or in vivo investigation for their potential use for bone tissue engineering strategies (Leach and Mooney, 2004; Stevens et al., 2008). Indeed, there is no agreement on which biomaterial (or possible mixture) is optimal for bone biofabrication, and the selection is constrained to the AMT employed. Moreover, some AMTs (e.g., stereolithography) require cytotoxic post-processing procedures, while laser sintering can cause biomaterial thermos degradation, with a loss of minute microstructure that, as a consequence, affects material porosity and cell viability (Stevens et al., 2008; Ferris et al., 2013; Gibbs et al., 2014; Tang et al., 2016).

The increasing advances in materials science and engineering has improved the development of the so-called smart materials, in particular polymeric smart materials, for a wide number of applications including bone tissue engineering ones (Stuart et al., 2010; Kumari et al., 2011; Ribeiro et al., 2015). The smart materials display reproducible, significant, and stable variations of at least one of their property when subjected to external stimuli and are usually classified based on the output response (e.g., piezoelectric materials, shape memory materials, temperature responsive polymers, conductive polymers, etc.) (Jeong and Gutowska, 2002).

The interest in the application of active materials is related to the fact that electrical signals control many of the major function in human cells and organs (Moore, 1975; Foulds and Barker, 1983; Ribeiro et al., 2015). For instance, bone tissue adaptation and remodeling are determined by a feedback mechanism that involves electromechanical processes due to its piezoelectric nature. It has been shown that small applied electric fields can guide the movement and migration of a variety of different cell types, thus improving in vivo tissue healing (Moroni et al., 2015; Ribeiro et al., 2015). Thus, conductive polymers such as polypyrrole (PPy), polyaniline (PANI), and carbon nanotubes (CNTs) incorporated into non-conductive polymers, both to provide structural support and to direct cell growth, have been tested for tissue and biomedical engineering applications (MattioliBelmonte et al., 2003, 2005, 2012; Harrison and Atala, 2007).

Several natural and synthetic materials could be used to generate active scaffold for tissue regeneration mainly in the form of microspheres, fibers, porous membranes, hydrogels, and sponges (Dhandayuthapani et al., 2011). Porous scaffolds have been generally obtained by traditional techniques (i.e., solvent casting/salt leaching, phase separation, gas foaming, gel casting, etc.) (Fallahiarezoudar et al., 2015) but, in order to overcome the inaccurate and limited interconnectivity pore morphology, electrospinning was also used (O'Brien, 2011). Indeed, few studies used AMT for the production of piezoelectric scaffolds (Moroni et al., 2015; Rana et al., 2015; Di Luca et al., 2016), and among these, PAM was used to realize bone-like structure scaffolds composed of CNT and polycaprolactone able to sustain osteoblast-like cell proliferation and modulate cell morphology (Mattioli-Belmonte et al., 2012).

A last generation of materials for the building up of scaffolds are polyhydroxyalkanoates (PHAs), a family of biopolyesters produced by microorganisms as intracellular carbon and energy storage compounds under unstable growth conditions (Williams and Martin, 2002; Chen, 2009). They can exist as homopolymers or copolymers of two or more hydroxyalkanoic acids, and several polymers of this family have been provided (Goonoo et al., 2016). Due to their variable composition, PHAs display diverse physicochemical properties and different rates of degradation in biological media, thereby maintaining their mechanical strength from short to prolonged amount of time (Yoshie and Inoue, 
2005). Even if PHA-based scaffolds demonstrated biocompatibility with different cell types (Goonoo et al., 2016), the use of PHAs is threatened by their poor mechanical properties, as most polymers derived from natural sources. To improve physicochemical properties, thus matching biological requirements of the different human tissues, PHAs have been blended with ceramics and polymers (e.g., gelatin, silk, and collagen). These copolymers have been used mainly with traditional techniques or with electrospinning, and no data are available on the generation of composite scaffolds with other AMT (Goonoo et al., 2016). Indeed, PHA/ceramic composites showed good in vitro and in vivo bioactivity and bone regenerating potential. Moreover, the addition of angiogenic growth factors and the possible monitoring of surface/topographical properties will enable to avoid problems such as poor vascularization and cell penetration [see Goonoo et al. (2016) for details].

\section{CELL-BIOMATERIAL INTERACTION}

In vivo, cells are subjected to a combination of biochemical and physical factors that regulate their functional behavior (Fernandez-Yague et al., 2015).

Mechanical stimulus has been identified for a long time as a key player in the adaptation of the musculoskeletal tissues to their function, and cells are known to perceive and respond to the environmental physical cues as well as to those of tissue scaffolds. Therefore, the optimization of cell-material interactions is critical in tissue engineering, and there is increasing agreement that material physical properties (i.e., topography, geometry, porosity, and stiffness) can be used to direct guide biological results similar to the traditional approaches that involves chemistry or biomolecules (Engler et al., 2006; Mitragotri and Lahann, 2009).

Osteogenic cells respond to mechanical stimuli (Mattei et al., 2015), and several microfabricated devices have been created to induce and/or monitor cell responses to biomechanical forces and/or biochemical gradients in vitro (Kim and $\mathrm{Ma}, 2012$ ). These devices can be used to analyze the effect of perfusion on human MSCs in a controlled way (Malizos and Papatheodorou, 2005; Bose et al., 2012), firmly evaluating the effect of cell seeding density and biomolecules on osteogenesis and angiogenesis (Das and Botchwey, 2011).

Different surface modification methods, such as oxidization, electrochemical deposition, or anodization via cathodic pre-treatment, have been used to further increase biomaterial biocompatibility and/or osteoinductivity (Hutmacher and Cool, 2007; Huang et al., 2014; Kundu et al., 2014). AMT can be used to precisely produce monotonic or graded topographical features on a biomaterial (Mattioli-Belmonte et al., 2015) and micropatterning that improves cell adhesion through focal adhesion formation (Dalby et al., 2014). The latter topological modifications can take the form of micro- and nanoscale protrusions, pits or grooves, able to direct or influence stem cell differentiation (Biggs et al., 2009; Oh et al., 2009). On the other side, since osteoclasts sense surface roughness at the resorption-sealing zone through forces applied at different heights and surface angles, biomaterials with 0.1-1 $\mu \mathrm{m}$ surface cracks can enhance osseointegration of the implant (Leijten et al., 2015).
It is clear that several factors contribute to mediating cell-material interaction, which is an intensely studied and complicated process. An ordered and regular microstructure with a smooth surface can improve material biocompatibility (Mattioli-Belmonte et al., 2008). Changing in biomaterial surface chemistry or scaffold geometry also affects cell adhesion, migration, and differentiation (Brydone et al., 2010; Bose et al., 2012).

Therefore, expressly planned micropatterning are not only capable to generate a unique topographical surface to monitor cell shape, alignment, and cell-cell and cell-matrix contact in basic stem cell biology study but could also be integrated with 3D bioprinting to develop micropattered 3D structure, thus inducing stem cell-based tissue regeneration. ECM coating on a definite topographical structure is able to induce even more precise and powerful stem cell differentiation along with soluble factors and mechanical forces (Lin et al., 2016).

\section{LIMITS IN BONE BIOFABRICATION}

One of the key factors for the success of any form of transplant (either with or without the presence of scaffolds) is cell viability: transplanted cells must survive for a sufficient period in order to perform their biological function. In biofabrication approaches, the printed cells need first to survive during all processing and printing steps. Extreme environmental and culture conditions, changes before, during, and/or following printing can adversely affect cell homeostasis or result in cell damage and death (Leach and Mooney, 2004; Bose et al., 2012). Depending on the approach adopted, bioprinting can result in decreased cell viability (Leach and Mooney, 2004; Nair et al., 2009; Brydone et al., 2010; Gruene et al., 2011), with no effect documented for laser-assisted bioprinting (Schiele et al., 2010; Ali et al., 2014).

Cell viability can be also affected by the biomaterial compatibility. Many hydrogels, which are attractive given their high cytocompatibility, have been applied in tissue engineering strategies (Bryant et al., 2007; Fedorovich et al., 2011). Indeed, even if hydrogels have been planned to furnish cells with a completely hydrated 3D environment similar to the natural ECM, their poor inherent mechanical strength limits their use in 3D biofabricated bone tissue-engineered constructs (Malda et al., 2013). The increase in polymer concentration and crosslinking improves hydrogel mechanical properties, but it can affect the biofabrication process itself, both interfering with the process and/or extending the fabrication time. These aspects in turn lead to a reduction in cell viability and functionality (Hutmacher and Cool, 2007; Rouillard et al., 2011; Tang et al., 2016). In order to exceed the lack of mechanical strength of the hydrogel, hybrid 3D constructs consisting of thermoplastic biomaterials and cell-laden hydrogels have been suggested. These systems include non-woven scaffolds manufactured via solution electrospinning techniques and scaffolds fabricated via 3D printing (Visser et al., 2015).

Bone is a metabolically active tissue with an internal vasculature and osteocytes located no more than $100 \mu \mathrm{m}$ from an intact capillary (Muschler et al., 2004). Angiogenesis, which arises spontaneously after bone grafting, is triggered by inflammation. This capillary network is transient and reverts within 
few weeks. The host-derived neovascularization of the implant is slow and, consequently, insufficient in the case of constructs of a relevant size. To date, vascularization remains a challenging technical obstacle in biofabrication and has prevented the development of clinically successful engineered constructs (Santo and Reis, 2010; Nguyen and Burg, 2015). In order to solve this issue, strategies involving the use of coculture systems, perfusion bioreactors, biomaterials, and growth factors to direct cell behavior are under investigation (Allori et al., 2008; Kyriakidou et al., 2008; Nguyen et al., 2012; Mercado-Pagan et al., 2015; Nguyen and Burg, 2015). Microscale technologies provide plasticity in generating accurate $3 \mathrm{D}$ architectures with embedded vascularized and capillary networks. Present methods include the formation of a ditch precasted into one layer before a second layer is aligned and deposited, forming laminated channel(s) or grooves in a repetitive way (Miller et al., 2012; Costa et al., 2014). Using this method, Moroni et al. (2006) formed microscale 3D scaffolds with organized hollow fibers with governable diameter and thickness that could be used as a vascularized network.

Scaffold pores are essential for the formation of bone tissue, since they enable cell migration and ingrowth as well as nutrient diffusion for cell survival (Karageorgiou and Kaplan, 2005). In general, scaffolds with pore sizes greater than $50 \mu \mathrm{m}$ allow nutrient diffusion but show lower cell adhesion and intracellular signaling. For an effective cell growth, pore size must be "tailored" based on different cell types needs. For instance, larger pores are useful for osteoblasts growth, while fibroblasts preferred smaller pores (Oh et al., 2007). Narayan and Venkatraman (2008) reported that the in vitro growth of endothelial cell on PLGA scaffolds was enhanced on 5-20 $\mu \mathrm{m}$ pore sizes, with lower interpore distance. However, this was in contrast to some in vivo studies that showed as a higher porosity permits for faster bone ingrowth and vascularization. Improved bone formation was observed in hydroxyapatite scaffolds with $300-400 \mu \mathrm{m}$ pore sizes implanted in rats, suggesting that a fast scaffold vascularization determines an osteogenic microenvironment (Klenke et al., 2008; Bai et al., 2010). Conflicting results in these studies stress the limitations of in vitro researches in predicting in vivo results as well as the requirement to assess the best pore sizes for each cell type used for bone tissue engineering. Moreover, porous or rough materials integrate in a less fibrotic, better-vascularized way in comparison with smooth, compact forms.

An important reason in implant failure is associated with a foreign body reaction: biocompatible biomaterials become encapsulated and are phagocytized by macrophages. Indeed, it has also been shown that porous biomaterials with pore of $30-40 \mu \mathrm{m}$ in size displayed excellent healing with a pro-healing functionality of macrophages, regardless of polymer composition or implant site (Osathanon et al., 2008).

\section{CLINICAL TRANSLATION}

A basic problem for a positive translation of any cell therapy for regenerative medicine purposes is still their large-scale production. In this respect, the bioprocessing phases of the producing process must be reproducible and scalable, in accordance with good clinical and manufacturing practice standards, safe for patients, and economically sustainable (Martin et al., 2014). Regardless of high resolution and reproducibility, laser-assisted bioprinting techniques offer low number and small-scale manufacture of constructs (Guillotin et al., 2014), and inkjet bioprinting has similar limitations (Guillotin and Guillemot, 2011), while extrusion methods shows a higher resolution than inkjet-based printing in producing structures suitable for clinical use (Khatiwala et al., 2012).

The standard file format used to control AMT bioprinters is STL. While it works for solid objects with small complexity, STL is an unfeasible format if internal pore architecture is an integral part of the computer-aided design (Melchels et al., 2012). New methods to create porous models from medical imaging-derived data are therefore under evaluation in order to enable the study of the effects of biomechanical forces on bone remodeling (Wang and Mondry, 2005).

In vivo animal models can produce several relevant data on bone repair processes and testing the effectiveness of bioprinted or biofabricated bone constructs. These researches generally encompass big numbers of animals that raise ethical concerns and are expensive. The development of ex vivo organ cultures (Smith et al., 2014) as well as the use of chick chorioallantoic membranes for the study of vascularization, biomaterial compatibility, and growth factors (Nowak-Sliwinska et al., 2014) have facilitated the reduction of animals used for the study of bone repair process. Despite these advances, there are still few comparable data in the literature on long-term in vitro and in vivo characterization of bioprinted and biofabricated bone constructs. The improve accuracy of in silico predictive models would also reduce the numbers of animals used in in vivo studies (Fedorovich et al., 2011; Ferretti et al., 2015; Vozzi et al., 2016).

Modern microscopy techniques have helped in the evolution of biomaterials, from their composition to their interactions (Vielreicher et al., 2013). A major advantage of these techniques in the analysis of tissue constructs is that most of them are non-destructive. Table 7 summarized some of the microscopic techniques used to study bone tissue engineering.

When it is necessary for imaging cells within scaffolds, the limited penetration depths for most microscopy techniques is a major limitation. The introduction of multi-photon microscopy as well as advances in microcomputed tomography has allowed for slice-wise optical sectioning and 3D reconstruction of these constructs. These improvements overcome some of the limitations associated with traditional light microscopy. However, the computing power and storage space necessary to perform, analyze, and collect the data obtained with these methods is massive, even by today's standards in information technology.

Finally, biofabrication is a quickly developing field with the capacity to change drastically the actual medical treatments. However, this idea requires integrated bioprinting platforms able to manage multiple materials to tissue constructs with structural integrity and of clinically relevant scales. Recently, Kang et al. (2016) developed such a platform and effectively produced different tissue types in vivo, opening a breakthrough for the clinical 
TABLE 7 | Imaging methods used in bone tissue engineering. ${ }^{a}$

\begin{tabular}{|c|c|c|c|c|c|c|}
\hline Method & Physical principles & Imaging depth & 3D imaging & $\begin{array}{l}\text { Acquisition } \\
\text { speed }\end{array}$ & Invasiveness & Specificity \\
\hline$\mu \mathrm{CT}$ & X-ray diffraction & Whole body & Excellent & Average & $\begin{array}{l}\text { Low for hard } \\
\text { tissue }\end{array}$ & Average \\
\hline $\begin{array}{l}\text { Confocal light } \\
\text { microscopy }\end{array}$ & 1-photon fluorescence: 200 & $<100 \mu \mathrm{m}$ & Excellent & Good & Low & Excellent \\
\hline Light microscopy & Light diffraction and interference & N.A. & Poor & Excellent & Low & $\begin{array}{l}\text { Low without } \\
\text { staining }\end{array}$ \\
\hline SEM/TEM & Electron diffraction & N.A./ <200 nm & Very poor & Very poor & Very high & Excellent \\
\hline $\begin{array}{l}\text { Non-linear optical } \\
\text { microscopy }\end{array}$ & $\begin{array}{l}\text { 2-photon fluorescence/second harmonic generation/ } \\
\text { coherent anti-Stokes Raman scattering }\end{array}$ & $<1,000 \mu \mathrm{m}$ & Excellent & Good & High & Excellent \\
\hline
\end{tabular}

$\mu C T$, microcomputed tomography; SEM, scanning electron microscopy; TEM, transmission electron microscopy; N.A., not applicable; 3D, three dimensional.

Invasiveness indicates the degree of tissue damage.

aModified from Tang et al. (2016) and Vielreicher et al. (2013).

translation of this technology, even if to achieve this final goal, further steps and challenges remain (Malda and Groll, 2016).

\section{CONCLUSION}

Biofabrication using AMT offers a defined and organized approach for bone tissue generation in comparison with traditional techniques. Nevertheless, there are still significant challenges with biofabrication for the development of clinically relevant bone constructs. These problems are not only relative to the existing limitations in AMT but are also due to the possibility to obtain an appropriate vascularization of the structures as well as correct spatiotemporal biochemical and mechanical stimuli, to maximize osteogenesis and osseointegration. Advances in AMT, computational modeling, medical imaging and microscopy technology, bioreactor design, and biomaterial and drug development are therefore mandatory in order to face difficulties and improve the cost-effectiveness of biofabricated bone for clinical therapy, which at present is poor. Moreover, the correct cell selection for an effective clinical result must be taken into consideration.

\section{REFERENCES}

Ali, M., Pages, E., Ducom, A., Fontaine, A., and Guillemot, F. (2014). Controlling laser-induced jet formation for bioprinting mesenchymal stem cells with high viability and high resolution. Biofabrication 6, 045001. doi:10.1088/1758-5082/6/4/045001

Allori, A. C., Sailon, A. M., Clark, E., Cretiu-Vasiliu, C., Smay, J., Ricci, J. L., et al. (2008). Dynamic cell culture for vascularized bone engineering. J. Am. Coll. Surg. 207, S51-S52. doi:10.1016/j.jamcollsurg.2008.06.108

Arnsdorf, E. J., Jones, L. M., Carter, D. R., and Jacobs, C. R. (2009). The periosteum as a cellular source for functional tissue engineering. Tissue Eng. Part A 15, 2637. doi:10.1089/ten.TEA.2008.0244

Bai, F., Wang, Z., Lu, J., Liu, J., Chen, G., Lv, R., et al. (2010). The correlation between the internal structure and vascularization of controllable porous bioceramic materials in vivo: a quantitative study. Tissue Eng. Part A 16, 3791. doi:10.1089/ ten.TEA.2010.0148

Barron, J. A., Krizman, D. B., and Ringeisen, B. R. (2005). Laser printing of single cells: statistical analysis, cell viability, and stress Ann. Biomed. Eng. 33, 121. doi:10.1007/s10439-005-8971-x

Biggs, M. J. P., Richards, R. G., Gadegaard, N., Wilkinson, C. D. W., Oreffo, R. O. C., and Dalby, M. J. (2009). The use of nanoscale topography to modulate the dynamics of adhesion formation in primary osteoblasts and ERK/MAPK
It must also be underlined that all improvement in bone biofabrication will surely aid the knowledge and understanding of skeletal stem cell biology, cell interactions, and responses to external stimuli for bone development, formation, and remodeling related to the aging of population.

\section{AUTHOR CONTRIBUTIONS}

$\mathrm{MB}$ conceived and critically revised the whole manuscript. MO drafted and revised the section relative to cell sources and biomolecules. MF drafted and revised the section relative to the limits of biofabrication techniques. RP critically revised the whole manuscript.

\section{ACKNOWLEDGMENTS}

This study was supported by a project funded by the European Union under the Marie Curie Actions-IRSES (GA no. 612589) $\mathrm{CHETCH}-\mathrm{China}$ and Europe Taking Care of Healthcare Solutions.

signaling in STRO-1+ enriched skeletal stem cells. Biomaterials 30, 5094. doi:10.1016/j.biomaterials.2009.05.049

Bose, S., Roy, M., and Bandyopadhyay, A. (2012). Recent advances in bone tissue engineering scaffolds. Trends Biotechnol. 30, 546e554. doi:10.1016/ j.tibtech.2012.07.005

Bryant, S. J., Cuy, J. L., Hauch, K. D., and Ratner, B. D. (2007). Photo-patterning of porous hydrogels for tissue engineering. Biomaterials 28, 2978. doi:10.1016/ j.biomaterials.2006.11.033

Brydone, A. S., Meek, D., and Maclaine, S. (2010). Bone grafting, orthopaedic biomaterials, and the clinical need for bone engineering. Proc. Inst. Mech. Eng. H 224, 1329. doi:10.1243/09544119JEIM770

Castro-Silva, I. I., Zambuzzi, W. F., de Oliveira Castro, L., and Granjeiro, J. M. (2012). Periosteal-derived cells for bone bioengineering: a promising candidate. Clin. Oral Implants Res. 23, 1238. doi:10.1111/j.1600-0501.2011.02287.x

Catros, S., Fricain, J. C., Guillotin, B., Pippenger, B., Bareille, R., Remy, M., et al. (2011). Laser-assisted bioprinting for creating on-demand patterns of human osteoprogenitor cells and nano-hydroxyapatite. Biofabrication 3, 025001. doi:10.1088/1758-5082/3/2/025001

Catros, S., Guillemot, F., Nandakumar, A., Ziane, S., Moroni, L., Habibovic, P., et al. (2012). Layer-by-layer tissue microfabrication supports cell proliferation in vitro and in vivo. Tissue Eng. Part C Methods 18, 62. doi:10.1089/ten. TEC.2011.0382 
Chen, G. Q. (2009). A microbial polyhydroxyalkanoates (PHA) based bio- and materials industry. Chem. Soc. Rev. 38, 2434. doi:10.1039/b812677c

Chiu, L. L. Y., and Radisic, M. (2010). Scaffolds with covalently immobilized VEGF and angiopoietin-1 for vascularization of engineered tissues. Biomaterials 31 , 226. doi:10.1016/j.biomaterials.2009.09.039

Colnot, C. (2011). Cell sources for bone tissue engineering: insights from basic science. Tissue Eng. Part B Rev. 17, 449. doi:10.1089/ten.TEB.2011.0243

Costa, P. F., Vaquette, C., Baldwin, J., Chhaya, M., Gomes, M. E., Reis, R. L., et al. (2014). Biofabrication of customized bone grafts by combination of additive manufacturing and bioreactor knowhow. Biofabrication 6, 035006. doi:10.1088/1758-5082/6/3/035006

Cui, X. F., and Boland, T. (2009). Boland human microvasculature fabrication using thermal inkjet printing technology. Biomaterials 30, 6221. doi:10.1016/ j.biomaterials.2009.07.056

Dalby, M. J., Gadegaard, N., and Oreffo Harnessing, R. O.C. (2014). Nanotopography and integrin-matrix interactions to influence stem cell fate. Nat. Mater. 13, 558. doi:10.1038/nmat3980

Das, A., and Botchwey, E. (2011). Evaluation of angiogenesis and osteogenesis. Tissue Eng. Part B Rev. 17, 403. doi:10.1089/ten.TEB.2011.0190

Dawson, J. I., Kanczler, J., Tare, R., Kassem, M., and Oreffo, R. O. C. (2014). Concise review: bridging the gap: bone regeneration using skeletal stem cell-based strategies-where are we now? Stem Cells 32, 35. doi:10.1002/stem.1559

Dhandayuthapani, B., Yoshida, Y., Maekawa, T., and Kumar, D. S. (2011). Polymeric scaffolds in tissue engineering application: a review. Int. J. Polym. Sci. 2011, 19. doi:10.1155/2011/290602

Di Luca, A., Longoni, A., Criscenti, G., Lorenzo-Moldero, I., Klein-Gunnewiek, M., Vancso, J., et al. (2016). Surface energy and stiffness discrete gradients in additive manufactured scaffolds for osteochondral regeneration. Biofabrication 8, 015014. doi:10.1088/1758-5090/8/1/015014

Dicarlo, M., Bianchi, N., Ferretti, C., Orciani, M., Di Primio, R., and MattioliBelmonte, M. (2016). Evidence supporting a paracrine effect of IGF-1/VEGF on human mesenchymal stromal cell commitment. Cells Tissues Organs 201, 333. doi: $10.1159 / 000445346$

El Tamer, M. K., and Reis, R. L. (2009). Progenitor and stem cells for bone and cartilage regeneration. J. Tissue Eng. Regen. Med. 3, 327. doi:10.1002/term.173

Engler, A. J., Sen, S., Sweeney, H. L., and Discher, D. E. (2006). Matrix elasticity directs stem cell lineage specification. Cell 126, 677. doi:10.1016/j.cell.2006.06.044

Fallahiarezoudar, E., Ahmadipourroudposht, M., Idris, A., and Mohd Yusof, N. (2015). Application of response surface methodology in optimization of electrospinning process to fabricate (ferrofluid/polyvinyl alcohol) magnetic nanofibers. Mater. Sci. Eng. C 48, 556. doi:10.1016/j.msec.2015.02.008

Fan, W., Crawford, R., and Xiao, Y. (2008). Structural and cellular differences between metaphyseal and diaphyseal periosteum in different aged rats. Bone 42, 81. doi:10.1016/j.bone.2007.08.048

Fedorovich, N. E., Alblas, J., Hennink, W. E., Öner, F. C., and Dhert, W. J. (2011). A organ printing: the future of bone regeneration? Trends Biotechnol. 29, 601. doi:10.1016/j.tibtech.2011.07.001

Fedorovich, N. E., De Wijn, J. R., Verbout, A. J., Alblas, J., and Dhert, W. J. (2008). Three-dimensional fiber deposition of cell-laden, viable, patterned constructs for bone tissue printing. Tissue Eng. Part A 14, 127. doi:10.1089/ten.a.2007.0158

Fedorovich, N. E., Haverslag, R. T., Dhert, W. J. A., and Alblas, J. (2010). The role of endothelial progenitor cells in prevascularized bone tissue engineering: development of heterogeneous constructs. Tissue Eng. Part A 16, 2355. doi:10.1089/ ten.TEA.2009.0603

Fedorovich, N. E., Schuurman, W., Wijnberg, H. M., Prins, H. J., van Weeren, P. R., Malda, J., et al. (2012). Biofabrication of osteochondral tissue equivalents by printing topologically defined, cell-laden hydrogel scaffolds. Tissue Eng. Part C Methods 18, 33. doi:10.1089/ten.TEC.2011.0060

Fernandez-Yague, M. A., Abbah, S. A., McNamara, L., Zeugolis, D. I., Pandit, A., and Biggs, M. J. (2015). Biomimetic approaches in bone tissue engineering: integrating biological and physicomechanical strategies. Adv. Drug Deliv. Rev. 84, 1. doi:10.1016/j.addr.2014.09.005

Ferretti, C., Lucarini, G., Andreoni, C., Salvolini, E., Bianchi, N., Vozzi, G., et al. (2015). Human periosteal derived stem cell potential: the impact of age. Stem Cell. Rev. 11, 487. doi:10.1007/s12015-014-9559-3

Ferretti, C., and Mattioli-Belmonte, M. (2014). Periosteum derived stem cells for regenerative medicine proposals: boosting current knowledge. World J. Stem Cells. 26, 266. doi:10.4252/wjsc.v6.i3.266
Ferretti, C., Vozzi, G., Falconi, M., Orciani, M., Gesi, M., Di Primio, R., et al. (2014). Role of IGF1 and IGF1/VEGF on human mesenchymal stromal cells in bone healing: two sources and two fates. Tissue Eng. Part A 20, 2473. doi:10.1089/ten

Ferris, C. J., Gilmore, K. G., Wallace, G. G., and in het Panhuis, M. (2013). Biofabrication: an overview of the approaches used for printing of living cells. App. Microbiol. Biotechnol. 97, 4243. doi:10.1007/s00253-013-4853-6

Foulds, I. S., and Barker, A. T. (1983). Human skin battery potentials and their possible role in wound healing. Br. J. Dermatol. 109, 515. doi:10.1111/ j.1365-2133.1983.tb07673.x

Gao, G. F., Schilling, A. F., Yonezawa, T., Wang, J., Dai, G. H., and Cui, X. F. (2014). Bioactive nanoparticles stimulate bone tissue formation in bioprinted three-dimensional scaffold and human mesenchymal stem cells. Biotechnol. J. 9, 1304. doi:10.1002/biot.201400305

Gibbs, D. M., Vaezi, M., Yang, S., and Oreffo, R. O. C. (2014). Hope versus hype: what can additive manufacturing realistically offer trauma and orthopedic surgery? Regen. Med. 9, 535. doi:10.2217/rme.14.20

Goonoo, N., Bhaw-Luximon, A., Passanha, P., Esteves, S. R., and Jhurry, D. (2016). Third generation poly(hydroxyacid) composite scaffolds for tissue engineering. J. Biomed. Mater. Res. B Appl. Biomater. doi:10.1002/jbm.b.33674

Gothard, D., Smith, E. L., Kanczler, J. M., Rashidi, H., Qutachi, O., Henstock, J. M., et al. (2014). Tissue engineered bone using select growth factors: a comprehensive review of animal studies and clinical translation studies in man. Eur. Cell Mater. 28, 166-208. doi:10.22203/eCM.v028a13

Gruene, M., Deiwick, A., Koch, L., Schlie, S., Unger, C., Hofmann, N., et al. (2011). Laser printing of stem cells for biofabrication of scaffold-free autologous grafts. Tissue Eng. Part C Methods 17, 79. doi:10.1089/ten.TEC.2010.0359

Guillotin, B., Catros, S., Keriquel, V., Souquet, A., Fontaine, A., Remy, M. J. C., et al. (2014). "Rapid prototyping of complex tissues with laser assisted bioprinting (LAB)," in Rapid Prototyping of Biomaterials: Principles and Applications (Cambridge: Woodhead Publishing), 156-175.

Guillotin, B., and Guillemot, F. (2011). Cell patterning technologies for organotypic tissue fabrication. Trends Biotechnol. 29, 183. doi:10.1016/j.tibtech.2010.12.008

Guillotin, B., Souquet, A., Catros, S., Duocastella, M., Pippenger, B., Bellance, S., et al. (2010). Laser assisted bioprinting of engineered tissue with high cell density and microscale organization. Biomaterials 31, 7250. doi:10.1016/ j.biomaterials.2010.05.055

Harrison, B. S., and Atala, A. (2007). Carbon nanotube applications for tissue engineering. Biomaterials 28, 344. doi:10.1016/j.biomaterials.2006.07.044

He, X., Ma, J., and Jabbari, E. (2008). Effect of grafting RGD and BMP-2 protein-derived peptides to a hydrogel substrate on osteogenic differentiation of marrow stromal cells. Langmuir 24, 12508. doi:10.1021/la802447v

Huang, C. F., Chiang, H. J., Lin, H. J., Hosseinkhani, H., Ou, K. L., and Pen, P. W. (2014). Comparison of cell response and surface characteristics on titanium implant with SLA and SLAffinity functionalization. J. Electrochem. Soc. 161, G15. doi:10.1149/2.084403jes

Hutmacher, D. W., and Cool, S. (2007). Concepts of scaffold-based tissue engineering-the rationale to use solid free-form fabrication techniques. J. Cell Mol. Med. 11, 654. doi:10.1111/j.1582-4934.2007.00078.x

Jeong, B., and Gutowska, A. (2002). Lessons from nature: stimuli-responsive polymers and their biomedical applications. Trends Biotechnol. 20, 305. doi:10.1016/ S0167-7799(02)01962-5

Kanczler, J. M., and Oreffo, R. O. (2008). Osteogenesis and angiogenesis: the potential for engineering bone. Eur. Cell. Mater. 15, 100-114. doi:10.22203/ eCM.v015a08

Kang, H. W., Lee, S. J., Ko, I. K., Kengla, C., Yoo, J. J., and Atala, A. (2016). A 3D bioprinting system to produce human-scale tissue constructs with structural integrity. Nat. Biotechnol. 34, 312-319. doi:10.1038/nbt.3413

Karageorgiou, V., and Kaplan, D. (2005). Porosity of 3D biomaterial scaffolds and osteogenesis. Biomaterials 26, 5474-5491. doi:10.1016/ j.biomaterials.2005.02.002

Khatiwala, C., Law, R., Shepherd, B., Dorfman, S., and Csete, M. (2012). 3D cell bioprinting for regenerative medicine research and therapies. Gene Ther. Reg. 7, 1230004. doi: $10.1142 / \mathrm{S} 1568558611000301$

Kim, J., and Ma, T. (2012). Bioreactor strategy in bone tissue engineering: pre-culture and osteogenic differentiation under two flow configurations. Tissue Eng. Part A 18, 2354. doi:10.1089/ten.TEA.2011.0674

Klenke, F. M., Liu, Y., Yuan, H., Hunziker, E. B., Siebenrock, K. A., and Hofstetter, W. (2008). Impact of pore size on the vascularization and osseointegration of 
ceramic bone substitutes in vivo. J. Biomed. Mater. Res. A 85A, 777. doi:10.1002/ jbm.a.31559

Kuhn, L. T., Ou, G. M., Charles, L., Hurley, M. M., Rodner, C. M., and Gronowicz, G. (2013). Fibroblast growth factor-2 and bone morphogenetic protein-2 have a synergistic stimulatory effect on bone formation in cell cultures from elderly mouse and human bone. J. Gerontol. A Biol. Sci. Med. Sci. 68, 1170. doi:10.1093/ gerona/glt018

Kumari, P., Tiwari, A., Prabaharan, M., and Li, S. (2011). "Smart polymeric materials emerging for biological applications," in Smart Polymer Materials for Biomedical Applications, eds S. Li, A. Tiwari, M. Prabaharan, and S. Aryal (Hauppauge, NY: Nova Science Publishers), 7.

Kundu, J., Pati, F., Shim, J. H., and Cho, D. W. (2014). "Rapid prototyping technology for bone regeneration," in Rapid Prototyping of Biomaterials: Principles and Applications (Cambridge: Woodhead Publishing), 254.

Kusuhara, H., Isogai, N., Enjo, M., Otani, H., Ikada, Y., Jacquet, R., et al. (2009). Tissue engineering a model for the human ear: assessment of size, shape, morphology, and gene expression following seeding of different chondrocytes. Wound Repair Regen. 17, 136. doi:10.1111/j.1524-475X.2008.00451.x

Kwon, D. S., Spevak, M. R., Fletcher, K., and Kleinman, P. K. (2002). Physiologic subperiosteal new bone formation: prevalence, distribution, and thickness in neonates and infants. AJR Am. J. Roentgenol. 179, 985. doi:10.1111/j.1524-475X.2008.00451.x

Kyriakidou, K., Lucarini, G., Zizzi, A., Salvolini, E., Mattioli Belmonte, M., Mollica, F., et al. (2008). Dynamic co-seeding of osteoblast and endothelial cells on 3D polycaprolactone scaffolds for enhanced bone tissue engineering. J. Bioact. Compat. Polym. 23, 227. doi:10.1177/0883911508091905

Leach, J. K., and Mooney, D. J. (2004). Bone engineering by controlled delivery of osteoinductive molecules and cells. Expert Opin. Biol. Ther. 7, 1015. doi:10.1517/14712598.4.7.1015

Leijten, J., Chai, Y. C., Papantoniou, I., Geris, L., Schrooten, J., and Luyten, F. P. (2015). Cell based advanced therapeutic medicinal products for bone repair: keep it simple? Adv. Drug Deliv. Rev. 84, 30. doi:10.1016/j.addr.2014.10.025

Lin, X., Shi, Y., Cao, Y., and Liu, W. (2016). Recent progress in stem cell differentiation directed by material and mechanical cues. Biomed. Mater. 11, 014109. doi:10.1088/1748-6041/11/1/014109

Liu, J., Yu, F., Sun, Y., Jiang, B., Zhang, W., Yang, J., et al. (2015a). Concise reviews: characteristics and potential applications of human dental tissue-derived mesenchymal stem cells. Stem Cells 33, 627. doi:10.1002/stem.1909

Liu, Y., Chan, J. K., and Teoh, S. H. (2015b). Review of vascularised bone tissue engineering strategies with a focus on co-culture systems. J. Tissue Eng. Regen. Med. 9, 85. doi:10.1002/term.1617

Mafi, R., Hindocha, S., Mafi, P., Griffin, M., and Khan, W. S. (2011). Sources of adult mesenchymal stem cells applicable for musculoskeletal applications - a systematic review of the literature. Open Orthop. J. 2, 242. doi:10.2174/18743 25001105010242

Malda, J., and Groll, J. (2016). A step towards clinical translation of biofabrication. Trends Biotechnol. 34, 356. doi:10.1016/j.tibtech.2016.03.003

Malda, J., Visser, J., Melchels, F. P., Jungst, T., Hennick, W. E., Dhert, W. J. A., et al. (2013). 25th anniversary article: engineering hydrogels for biofabrication. $A d v$. Mater. 25, 5011. doi:10.1002/adma.201302042

Malizos, K. N., and Papatheodorou, L. K. (2005). The healing potential of the periosteum: molecular aspects. Injury 36, S13. doi:10.1016/j.injury.2005.07.030

Marolt, D., Knezevic, M., and Vunjak-Novokovic, G. (2010). Bone tissue engineering with human stem cells. Stem Cell Res. Ther. 4, 10. doi:10.1186/scrt10

Martin, I., Simmons, P. J., and Williams, D. F. (2014). Manufacturing challenges in regenerative medicine. Sci. Transl. Med. 6, 232fs16. doi:10.1126/ scitranslmed. 3008558

Matsushima, S., Isogai, N., Jacquet, R., Lowder, E., Tokui, T., and Landis, W. J. (2011). The nature and role of periosteum in bone and cartilage regeneration. Cells Tissues Organs 194, 320. doi:10.1159/000324642

Mattei, G., Ferretti, C., Tirella, A., Ahluwalia, A., and Mattioli-Belmonte, M. (2015). Decoupling the role of stiffness from other hydroxyapatite signaling cues in periosteal derived stem cell differentiation. Sci. Rep. 5, 10778. doi:10.1038/ srep 10778

Mattioli-Belmonte, M., De Maria, C., Vitale-Brovarone, C., Baino, F., Dicarlo, M., and Vozzi, G. (2015). Pressure-activated microsyringe (PAM) fabrication of bioactive glass-poly(lactic-co-glycolic acid) composite scaffolds for bone tissue regeneration. J. Tissue Eng. Regen. Med. 29. doi:10.1002/term.2095
Mattioli-Belmonte, M., Gabbanelli, F., Marcaccio, M., Giantomassi, F., Tarsi, R., Natali, D., et al. (2005). Bio-characterisation of tosylate-doped polypyrrole films for biomedical improvements. Mat. Sci. Eng. C 25, 43. doi:10.1016/ j.msec.2004.04.002

Mattioli-Belmonte, M., Giavaresi, G., Biagini, G., Virgili, L., Giacomini, M., Fini, M., et al. (2003). Tailoring biomaterial compatibility: in vivo tissue response versus in vitro cell behavior. Int. J. Artif. Organs 26, 1077-1087.

Mattioli-Belmonte, M., Vozzi, G., Kyriakidou, K., Pulieri, E., Lucarini, G., Vinci, B., et al. (2008). Rapid-prototyped and salt-leached PLGA scaffolds condition cell morpho-functional behavior. J. Biomed. Mater. Res. A 85, 466-476. doi:10.1002/ jbm.a. 31483

Mattioli-Belmonte, M., Vozzi, G., Whulanza, Y., Seggianib, M., Fantauzzic, V., Orsini, G., et al. (2012). Tuning polycaprolactone-carbon nanotube composites for bone tissue engineering scaffolds. Mat. Sci. Eng. C 32, 152. doi:10.1016/ j.msec.2012.07.046

Melchels, F. P. W., Domingos, M. A. N., Klein, T. J., Malda, J., Bartolo, P. J., and Hutmacher, D. W. (2012). Additive manufacturing of tissues and organs. Prog. Polym. Sci. 37, 1079. doi:10.1016/j.progpolymsci.2011.11.007

Mercado-Pagan, A. E., Stahl, A. M., Shanjani, Y., and Yang, Y. (2015). Vascularization in bone tissue engineering constructs. Ann. Biomed. Eng. 43, 718. doi:10.1007/ s10439-015-1253-3

Miller, J. S., Stevens, K. R., Yang, M. T., Baker, B. M., Nguyen, D. H., Cohen, D. M., et al. (2012). Rapid casting of patterned vascular networks for perfusable engineered three-dimensional tissues. Nat. Mater. 11, 768. doi:10.1038/nmat3357

Mitragotri, S., and Lahann, J. (2009). Physical approaches to biomaterial design. Nat. Mater. 8, 15. doi:10.1038/nmat2344

Moore, A. D. (1975). Electrostatic discharges for treating skin lesions: does it deserve some new research? Med. Instrum. 9, 274.

Moroni, L., Nandakumar, A., de Groot, F. B., van Blitterswijk, C. A., and Habibovic, P. (2015). Plug and play: combining materials and technologies to improve bone regenerative strategies. J. Tissue Eng. Regen. Med. 9, 745. doi:10.1002/term.1762

Moroni, L., Schotel, R., Sohier, J., De Wijn, J. R., and van Blitterswijk, C. A. (2006). Polymer hollow fiber three-dimensional matrices with controllable cavity and shell thickness. Biomaterials 27, 5918. doi:10.1016/j.biomaterials.2006. 08.015

Mourino, V., Cattalini, J. P., Roether, J. A., Dubey, P., Roy, I., and Boccaccini, A. R. (2013). Composite polymer-bioceramic scaffolds with drug delivery capability for bone tissue engineering. Expert Opin. Drug. Deliv. 10, 1353. doi:10.1517/ 17425247.2013 .808183

Muschler, G. F., Nakamoto, C., and Griffith, L. G. (2004). Engineering principles of clinical cell-based tissue engineering. J. Bone Joint Surg. Am. 86A, 1541-1558. doi:10.2106/00004623-200407000-00029

Nair, K., Gandhi, M., Khalil, S., Yan, K. C., Marcolongo, M., Barbee, K., et al. (2009). Characterization of cell viability during bioprinting processes. Biotechnol. J. 4, 1168. doi:10.1002/biot.200900004

Narayan, D., and Venkatraman, S. S. (2008). Effect of pore size and interpore distance on endothelial cell growth on polymers. J. Biomed. Mater. Res. A 87A, 710. doi:10.1002/jbm.a.31749

Nguyen, D. T., and Burg, K. J. (2015). Bone tissue engineering and regenerative medicine: targeting pathological fractures. J. Biomed. Mater. Res. A. 103, 420-429. doi:10.1002/jbm.a.35139

Nguyen, L. H., Annabi, N., Nikkhah, M., Bae, H., Binan, L., Park, S., et al. (2012). Vascularized bone tissue engineering: approaches for potential improvement. Tissue Eng. Part B Rev. 18, 363. doi:10.1089/ten.teb.2012.0012

Nowak-Sliwinska, P., Segura, T., and Iruela-Arispe, M. L. (2014). The chicken chorioallantoic membrane model in biology, medicine and bioengineering. Angiogenesis 17, 779. doi:10.1007/s10456-014-9440-7

O’Brien, C. M., Holmes, B., Faucett, S., and Zhang, L. G. (2014). Three-dimensional printing of nanomaterial scaffolds for complex tissue regeneration. Tissue Eng. Part B Rev. 21, 103. doi:10.1089/ten.teb.2014.0168

O’Brien, F. J. (2011). Biomaterials and scaffolds for tissue engineering. Mater. Today 14, 88. doi:10.1016/S1369-7021(11)70058-X

O'Driscoll, S. W., and Fitzsimmons, J. S. (2001). The role of periosteum in cartilage repair: review. Clin. Orthop. Relat. Res. 391, S190-S207. doi:10.1097/00003086-200110001-00019

O’Driscoll, S. W., Saris, D. B., Ito, Y., and Fitzsimmons, J. S. (2001). The chondrogenic potential of periosteum decreases with age. J. Orthop. Res. 19, 95. doi:10.1016/S0736-0266(00)00014-0 
Oh, S. H., Brammer, K. S., Li, Y. S., Teng, D., Engler, A. J., Chien, S., et al. (2009). Stem cell fate dictated solely by altered nanotube dimension. Proc. Natl. Acad. Sci. U.S.A. 106, 2130. doi:10.1073/pnas.0813200106

Oh, S. H., Park, I. K., Kim, J. M., and Lee, J. H. (2007). In vitro and in vivo characteristics of PCL scaffolds with pore size gradient fabricated by a centrifugation method. Biomaterials 28, 1664. doi:10.1016/j.biomaterials.2006.11.024

Orciani, M., and Di Primio, R. (2013). Skin-derived mesenchymal stem cells: isolation, culture, and characterization. Methods Mol. Biol. 989, 275. doi:10.1007/978-1-62703-330-5_21

Orciani, M., Di Primio, R., Ferretti, C., Orsini, G., Salvolini, E., Lazzarini, R., et al. (2012). In vitro evaluation of mesenchymal stem cell isolation possibility from different intra-oral tissues. J. Biol. Regul. Homeost. Agents 26, 57-63.

Orciani, M., Mariggiò, M. A., Morabito, C., Di Benedetto, G., and Di Primio, R. (2010). Functional characterization of calcium-signaling pathways of human skin-derived mesenchymal stem cells. Skin Pharmacol. Physiol. 23, 124. doi: $10.1159 / 000270383$

Oreffo, R. O. C., Cooper, C., Mason, C., and Clements, M. (2005). Mesenchymal stem cells lineage, plasticity, and skeletal therapeutic potential. Stem Cell. Rev. 1, 169. doi:10.1385/SCR:1:2:169

Oryan, A., Alidadi, S., Moshiri, A., and Maffuli, N. (2014). Bone regenerative medicine: classic options, novel strategies, and future directions. J. Orthop. Surg. Res. 9, 18. doi:10.1186/1749-799X-9-18

Osathanon, T., Linnes, M. L., Rajachar, R. M., Ratner, B. D., Somerman, M. J., and Giachelli, C. M. (2008). Microporous nanofibrous fibrin-based scaffolds for bone tissue engineering. Biomaterials 29, 4091. doi:10.1016/ j.biomaterials.2008.06.030

Phillippi, J. A., Miller, E., Weiss, L., Huard, J., Waggoner, A., and Campbell, P. (2008). Microenvironments engineered by inkjet bioprinting spatially direct adult stem cells toward muscle- and bone-like subpopulations. Stem Cells 26, 127. doi:10.1634/stemcells.2007-0520

Rana, D., Arulkumar, S., Vishwakarma, A., and Ramalingam, M. (2015). "Considerations on designing scaffold for tissue engineering," in Dental Sciences, ed. A. V. S. S. Ramalingam (Boston: Academic Press), 10.

Ribeiro, C., Sencadas, V., Correia, D. M., and Lanceros-Méndez, S. (2015). Piezoelectric polymers as biomaterials for tissue engineering applications. Colloids Surf. B Biointerfaces 136, 46. doi:10.1016/j.msec.2015. 02.008

Robey, P. G. (2011). Cell sources for bone regeneration: the good, the bad, and the ugly (but promising). Tissue Eng. Part B Rev. 17, 423. doi:10.1089/ten. teb.2011.0199

Rouillard, A. D., Berglund, C. M., Lee, J. Y., Polacheck, W. J., Tsui, Y., Bonassar, L. J., et al. (2011). Methods for photocrosslinking alginate hydrogel scaffolds with high cell viability. Tissue Eng. Part C Methods 17, 173. doi:10.1089/ten. tec. 2009.0582

Santo, M. I., and Reis, R. L. (2010). Vascularization in bone tissue engineering: physiology, current strategies, major hurdles and future challenges. Macromol. Biosci. 10, 12. doi:10.1002/mabi.200900107

Santo, V. E., Gomes, M. E., Mano, J. F., and Reis, R. L. (2013). Controlled release strategies for bone, cartilage, and osteochondral engineering - part II: challenges on the evolution from single to multiple bioactive factor delivery. Tissue Eng. Part B Rev. 19, 327. doi:10.1089/ten.teb.2012.0727

Sawkins, M. J., Mistry, P., Brown, B. N., Shakesheff, K., Bonassar, L. J., and Yang, J. (2015). Cell and protein compatible 3D bioprinting of mechanically strong constructs for bone repair. Biofabrication 7, 035004. doi:10.1088/1758-5090/7/3/035004

Schiele, N. R., Corr, D. T., Huang, Y., Raof, N. A., Xie, Y., and Chrisey, D. B. (2010). Laser-based direct-write techniques for cell printing. Biofabrication 2, 032001. doi:10.1088/1758-5082/2/3/032001

Seong, J. M., Kim, B. C., Park, J. H., Kwon, I. K., Mantalaris, A., and Hwang, Y. S. (2010). Stem cells in bone tissue engineering. Biomed. Mater. 5, 62001. doi:10.1088/1748-6041/5/6/062001

Simmons, C. A., Alsberg, E., Hsiong, S., Kim, W. J., and Mooney, D. J. (2004). Dual growth factor delivery and controlled scaffold degradation enhance in vivo bone formation by transplanted bone marrow stromal cells. Bone 35, 562 . doi:10.1016/j.bone.2004.02.027

Smith, E. L., Kanczler, J. M., Gothard, D., Roberts, C. A., Wells, J. A., White, L. J., et al. (2014). Evaluation of skeletal tissue repair, part 1: assessment of novel growth factor-releasing hydrogels in an ex vivo chick femur defect model. Acta Biomater. 10, 4186. doi:10.1016/j.actbio.2014.06.011

Stevens, B., Yang, Y., Mohandas, A., Stucker, B., and Nguyen, K. T. (2008). A review of materials, fabrication methods, and strategies used to enhance bone regeneration in engineered bone tissues. J. Biomed. Mater. Res. B Appl. Biomater. 85, 573. doi:10.1002/jbm.b.30962

Stuart, M. A., Huck, W. T., Genzer, J., Müller, M., Ober, C., Stamm, M., et al. (2010). Emerging applications of stimuli-responsive polymer materials. Nat. Mater. 9, 101. doi:10.1038/nmat2614

Szpalski, C., Barbaro, M., Sagebin, F., and Warren, S. M. (2012). Bone tissue engineering: current strategies and techniques part II: cell types. Tissue Eng. Part B Rev. 18, 258. doi:10.1089/ten.teb.2011.0440

Szulc, P., Seeman, E., Duboeuf, F., Sornay-Rendu, E., and Delmas, P. D. (2006). Bone fragility: failure of periosteal apposition to compensate for increased endocortical resorption in postmenopausal women. J. Bone Miner. Res. 21, 1856. doi:10.1359/jbmr.060904

Takeda, K., Gosiewska, A., and Peterkofsky, B. (1992). Similar, but not identical, modulation of expression of extracellular matrix components during in vitro and in vivo aging of human skin fibroblasts. J. Cell Physiol. 153, 450. doi:10.1002/ jcp. 1041530303

Tang, D., Tare, R. S., Yang, L. Y., Williams, D. F., Ou, K. L., and Oreffo, R. O. C. (2016). Biofabrication of bone tissue: approaches, challenges and translation for bone regeneration. Biomaterials 83, 363. doi:10.1016/j.biomaterials.2016.01.024

Tare, R. S., Mitchell, P. D., Kanczler, J., and Oreffo, R. O. C. (2012). Isolation, differentiation, and characterisation of skeletal stem cells from human bone marrow in vitro and in vivo. Methods Mol. Biol. 816, 83. doi:10.1007/978-1-61779415-5_7

Tirella, A., De Maria, C., Criscenti, G., Vozzi, G., and Ahluwalia, A. (2012). The PAM2 system: a multilevel approach for fabrication of complex three-dimensional microstructures. Rapid Prototyp. J. 4, 229. doi:10.1108/13552541211231725

Unger, R. E., Dohle, E., and Kirkpatrick, C. J. (2015). Improving vascularization of engineered bone through the generation of pro-angiogenic effects in co-culture systems. Adv. Drug Deliv. Rev. 94, 116. doi:10.1016/j.addr.2015.03.012

Vielreicher, M., Schurmann, S., Detsch, R., Schmidt, M. A., Buttgereit, A., Boccaccini, A., et al. (2013). Taking a deep look: modern microscopy technologies to optimize the design and functionality of biocompatible scaffolds for tissue engineering in regenerative medicine. J. R. Soc. Interf. 10, 20130263. doi:10.1098/rsif.2013.0263

Vishnubalaji, R., Manikandan, M., Al-Nbaheen, M., Kadalmani, B., Aldahmash, A., and Alajez, N. M. (2012). In vitro differentiation of human skin-derived multipotent stromal cells into putative endothelial-like cells. BMC Dev. Biol. 12:7. doi:10.1186/1471-213X-12-7

Visser, J., Melchels, F. P. W., Jeon, J. E., van Bussel, E. M., Kimpton, L. S., Byrne, H. M., et al. (2015). Reinforcement of hydrogels using three-dimensionally printed microfibers. Nat. Comms. 6, 6933. doi:10.1038/ncomms7933

Vorndran, E., Klammert, U., Ewald, A., Barralet, J. E., and Gbureck, U. (2010). Simultaneous immobilization of bioactives during 3D powder printing of bioceramic drug-release matrices. Adv. Funct. Mater. 20, 1585. doi:10.1002/ adfm.200901759

Vozzi, G., Lucarini, G., Dicarlo, M., Andreoni, C., Salvolini, E., Ferretti, C., et al. (2016). In vitro lifespan and senescent behavior of human periosteal derived stem cells. Bone 88, 1. doi:10.1016/j.bone.2016.04.013

Vozzi, G., Previti, A., De Rossi, D., and Ahluwalia, A. (2002). Microsyringe-based deposition of two dimensional and three-dimensional polymer scaffolds with a well-defined geometry for application to tissue engineering. Tissue Eng. 8, 1089. doi:10.1089/107632702320934182

Wang, F., Yu, M., Yan, X., Wen, Y., Zeng, Q., Yue, W., et al. (2011). Gingiva-derived mesenchymal stem cell-mediated therapeutic approach for bone tissue regeneration. Stem Cells Dev. 20, 2093. doi:10.1089/scd.2010.0523

Wang, Z., and Mondry, A. (2005). Volume-based non-continuum modeling of bone functional adaptation. Theor. Biol. Med. Model. 2, 6. doi:10.1186/1742-4682-2-6

Williams, S. F., and Martin, D. P. (2002). "Applications of PHAs in medicine and pharmacy," in Biopolymers, eds Y. Doi and A. Steinbuchel (Weinheim, Germany: Wiley-VCH), 95-99.

Yoshie, N., and Inoue, Y. (2005). Polyhydroxyalkanoates (PHAs), structure, composition and solution properties of polyesters. Biopolymers Online. doi:10.1002/3527600035.bpol3b06 
Young, S., Patel, Z. S., Kretlow, J. D., Murphy, M. B., Mountziaris, P. M., Baggett, L. S., et al. (2009). Dose effect of dual delivery of vascular endothelial growth factor and bone morphogenic protein- 2 on bone regeneration in a rat critical-size defect model. Tissue Eng. Part A 15, 2347. doi:10.1089/ten.tea.2008.0510

Zhang, H., Migneco, F., Lin, C. Y., and Hollister, S. J. (2010). Chemically-conjugated bone morphogenetic protein-2 on three-dimensional polycaprolactone scaffolds stimulates osteogenic activity in bone marrow stromal cells. Tissue Eng. Part A 16, 3441. doi:10.1089/ten.tea.2010.0132

Zhu, W., and Liang, M. (2015). Periodontal ligament stem cells: current status, concerns and future prospects. Stem Cells Int. 2015, 972313. doi:10.1155/2015/972313
Conflict of Interest Statement: The authors declare that the research was conducted in the absence of any commercial or financial relationships that could be construed as a potential conflict of interest.

Copyright (c) 2017 Orciani, Fini, Di Primio and Mattioli-Belmonte. This is an open-access article distributed under the terms of the Creative Commons Attribution License (CC BY). The use, distribution or reproduction in other forums is permitted, provided the original author(s) or licensor are credited and that the original publication in this journal is cited, in accordance with accepted academic practice. No use, distribution or reproduction is permitted which does not comply with these terms. 